\title{
Where Value Resides: Making Ecological Value Possible
}

\author{
Tom Greaves and Rupert Read*
}

\begin{abstract}
Distinguishing between the source and the locus of value enables environmental philosophers to consider not only what is of value, but also to try to develop a conception of valuation that is itself ecological. Such a conception must address difficulties caused by the original locational metaphors in which the distinction is framed. This is done by reassessing two frequently employed models of valuation, perception, and desire, and going on to show that a more adequate ecological understanding of valuation emerges when these models are fully contextualized in the intersecting life worlds of the ecological community. Ecological evaluation takes place in ongoing encounters between these worlds and a crucial part in this process is assigned to living beings that are "open-endedly open," that is, open only to what the world affords them and others, but open to an indefinite field of possible valuational encounters between all kinds of beings. Ecological valuation overcomes some of the conceptual failings of contemporary attempts to evaluate nature: "The Economics of Ecology and Biodiversity" and "Valuing Nature."
\end{abstract}

\section{INTRODUCTION}

In this paper we offer an account of valuation that understands values as "residing" neither in a pre-established human realm nor in a pre-established realm of natural beings, but rather as the ongoing encounters whereby the world we reside in comes to be established/maintained as a viable socio-ecological habitat. We argue that the substantial attention currently being paid to the value of ecological phenomena is inadequate on its own. Attention should also be paid to the ecology of value, that is, the ecological conditions in which valuations are made possible. ${ }^{1}$ We argue that much of the difficulty in the longstanding debates about the "location" of value stems from the set of metaphors of location in which it has been framed. ${ }^{2}$

\footnotetext{
* School of Politics, Philosophy, Language and Communication Studies, ARTS II, Room 01.29, University of East Anglia, Norwich, Norfolk NR4

7TJ, UK; emails: T.Greaves@uea.ac.uk and R.Read@uea.ac.uk. Greaves’ research interests are focused on phenomenology and environmental philosophy. Read's research interests are on the work of Wittgenstein and its impact on the sciences, especially the social sciences. The authors thank the participants in an interdisciplinary seminar on this paper at the University of East Anglia (UEA) in December 2011, especially Oskari Kuusela, the audience of the School of International Development (DEV) Departmental Seminar at UEA in February 2013, and the audience at the plenary session of the ISEE Annual Meeting in 2013. Finally they thank two very helpful anonymous referees for this journal, J. Baird Callicott and John O’Neill.

1 Throughout this paper we use terms ecology and ecological in the broad senses that they have developed in common usage to refer to the interconnectedness of living beings and their environments, rather than in the technical sense in which they refer exclusively to the objects and methods of ecological science.

${ }^{2}$ For amplification of this thought, see particularly George Lakoff and Mark Johnson, Philosophy
} 
A useful starting point is J. Baird Callicott's distinction between the source and the locus of value. ${ }^{3}$ An ecological conception of valuation requires some crucial modifications to this terminology. The source is not in one kind of being (nor even dependent upon specific capacities), but in encounters that take place between living beings, making up an ecological field. The location of value is in any being that can matter to those who make up an ecological field as a whole. This view allows us to uncouple the debate from the subject/object dichotomy and associated false dilemmas of realism and idealism about value. While there are certain kinds of capacity that make possible the opening of an ecological field, there are endless and open possibilities constituting the field and thus endless ways of valuing and being valued. Far more can be and is being valued and is of value than can be seen from simply concentrating on the capacities that make the presence of ecological value possible in the first place. ${ }^{4}$

Our understanding of ecological evaluation is to some extent comparable to Gibson's "ecological" approach to visual perception, based around the concept of "affordances." In sections two and three of this paper we address two significant models that have been employed in disputes about "where" value resides. The first presents valuing on the model of perception, the second on the model of desire. While each of these models has its advantage, potentially misleading conclusions can be drawn from fixing the source of valuation in these isolated capacities. In section four we develop what we consider to be a more adequate and more inclusive characterization of valuation. We suggest that valuation takes place as an ongoing "event" in which a panoply of living worlds intersect. To make a world habitable in this way is not to endorse an extreme biospherical egalitarianism; nor is it to say that every single individual will be able to survive and flourish in full. It requires us to recognize that all kinds of others are able to make the world habitable for themselves and cohabitable with us. While all living beings are open to a range of features and possibilities of the world around them, it is crucial to our argument that ecological valuation requires some beings to inhabit that ecological field that

in the Flesh (New York: Basic Books, 1999).

${ }^{3}$ J. Baird Callicott, "On the Intrinsic Value of Nonhuman Species," in The Preservation of Species, ed. Bryan G. Norton (Princeton: Princeton University Press, 1986), p. 142.

${ }^{4}$ While our approach is similar in a number of respects to that of John O'Neill, there are also significant differences. Foremost among these, we do not simply take what is "good for" a living being (or ecosystem), as fully established and evaluable by human subjects who in some sense still stand outside that system. O'Neill's strategic assumption that "only human agents are evaluating agents" (an assumption we disagree with, as will be seen as our paper unfolds) closes off the possibility of a fully fledged ecology of value. Our ecology of value leads us to return to the debate over the model of perception, and to elucidate the source vs. object distinction in a way that tends to undermine rather than reinforce the subject vs. object dichotomy. Finally, we do not concur that "metaethical commitments are independent of ethical ones." Even if it is true that fully fledged obligations/polices are not generally born from the heads of philosophers, possibilities for action are born from the ecology of value, as we argue in the final section of this paper. See John O'Neill, “The Varieties of Intrinsic Value," The Monist 75, no. 2 (1992): 119-37.

5 J. J. Gibson, The Ecological Approach to Visual Perception (Boston: Houghton Mifflin, 1979). See 
are "open-endedly open." That is, beings that are open not only to what the world affords them and their own kind, nor simply open to what the world affords others, such as seeing that a dog uses a chair as a sunshade. Open-endedly open beings are open to an indefinite field of possible encounters between themselves and others, but they are also open to actual and possible encounters that they are not themselves directly involved in (the significance of this point will become clearer in the "case study" that concludes this paper). This is the openness of human beings, some other animals and, most importantly perhaps, of humans-along-with-nonhumans.

\section{SENSING VALUES: FROM QUALITIES TO SHARED POTENTIAL}

Perception has been used as a model for thinking about the source and the locus of value, with the source understood as a process analogous to perceiving and the "locus" as analogous to the thing perceived. This way of understanding valuation can be very misleading if we bring certain preconceived ideas about perception with us; but it can also be potentially helpful in dispelling misconceptions. If we think of perception in terms of what might be called the reciprocity of potential we will be able to move toward a broadly ecological understanding of valuation. ${ }^{6}$

Thinking of values in terms of perceptual qualities makes it very tempting to think that values can and should be located either in the evaluators or the objects that they evaluate, because qualities are all-too-often understood simply and only as being located in or attached to objects. The thought that valuation is analogous to perception may be taken to entail either that the value is "in us," since it is we who must perceive the value, or that the value is "in the object," since we see it there.

Thinking through perception more carefully enables one to resist these tendencies and to begin to think about valuation in a more integrated and potentially illuminating way. The misleading tendency to think of valuation in terms of the pure attribution of qualities to objects by the perceiver or in terms of pure receptivity to those qualities in the object is resisted by paying attention to the whole process of perception.

The perceptual model for valuation is today often discussed in explicitly Lockean terms. John McDowell argues that this way of thinking about the experience of

section four below.

${ }^{6}$ There are numerous precedents for this line of thought. Max Scheler uses the term value-taking (Wertnehmung) to parallel the German word for perception (Wahrnehmung) which is literally truthtaking. The suggested parallel is clearly apposite to our argument. Scheler offers a strong argument against conceiving of values (and indeed colors) as "powers" or "dispositions" that adhere in objects in a Lockean sense. Values for Scheler are borne by objects, events, and acts, but are themselves ideal qualities. Max Scheler, Formalism in Ethics and Non-Formal Ethics of Values (Evaston: Northwestern University Press, 1973), pp. 15-18. Notwithstanding the importance of Scheler's thinking here, we argue below for a conception of value's conditions of possibility that rethinks "potential" along more Heideggerian lines and avoids some of the problematic absolutism of Scheler's value ideality. A contemporary equation of value-taking with truth-taking is to be found in Phil Hutchinson's Shame and 
value as "sensitivity to aspects of the world" is a good starting point for the exploration of the phenomenology of value, but he argues that instead of insisting that values must be thought of in terms of primary qualities we should think of them as secondary qualities. ${ }^{7}$ This claim of McDowell's allows us to underline what we think most helpful about the perceptual model. On this model, value is not thought of as attaching to the object valued or located in the subject valuing, but is what comes about and takes place between the two. The "secondary qualities, like all qualities, begin life as the shared potential between things.

We do not want to be revisionist with regard to ordinary human practice and language. Rather, setting out from McDowell's starting point, we inflect his conception of valuation with a resolute Wittgensteinian correction. ${ }^{8}$ The sky is blue when it is; life is precious, wonderful, surprising etc.. There is an obvious and ordinary sense in which "secondary" qualities of a thing really are qualities of that thing. But equally, one need not necessarily say that secondary qualities are qualities of, or powers in, the things. Rather, one could choose to say that "secondary qualities" are neither in the things nor in the beholders, but are broadly relational, constitutive of the lived world of the beings perceiving. ${ }^{9}$

Values are shared powers then, but we think it most helpful, most philosophically "therapeutic," 10 to suggest that, so far as the sensory is concerned, powers are never simply in one thing, as a central tenant of the Lockean tradition insists. Values as shared powers are brought about in encounters between things. It is these encounters that constitute and reshape the space of potentiality that those things inhabit, and this is also to constitute and reshape the space of possible valuations.

\section{DESIRING VALUES: FROM PRIZING TO LOVING}

A further aspect of our collective and reciprocal openness to the world that can and has been taken as a "model" for valuation as such is desire. For some this is because desire obviously includes "subjective" factors such as attitude

\footnotetext{
Philosophy (London: Palgrave, 2008).

${ }^{7}$ John McDowell, "Values and Secondary Qualities," in Mind, Value and Reality (Cambridge, Mass: Harvard University Press, 1998), pp. 131-32.

${ }^{8}$ It is worth looking in this connection at Peter Hacker's Appearance and Reality, as corrected by Marie McGinn in her "Wittgenstein's Remarks on Colour," Philosophy 66 (1991): 435-53.

${ }^{9}$ Alfred North Whitehead developed a historical critique of the idea of "simple location" resulting in a conception of qualities as moments in events or process that is in large part amenable to our argument. He went on to develop a notion of value as the concrete realization of every event: "Value' is the word I use for the intrinsic reality of an event." A. N.Whitehead, Science and the Modern World (New York: Pelican Mentor, 1948), p. 95 Where we depart from Whitehead is in his insistence on the realization of an event. Value must also be understood as coming about in the concrete potential for events formed in what we describe as an "ecological field."

${ }^{10}$ As should be obvious from the "back and forth" nature of our presentation in this section, there are hazards in every way of speaking hereabouts and hazards in "attaching" too closely to any particular way. Our suggestion should be understood as an attempt at situated correction of previous philosophical
} 
and motivation that they find lacking in perception. ${ }^{11}$ In particular, desire has a temporality, an openness to future possibilities, and inherent action-guidingness, which is not usually claimed for perception. These concerns about inadequacies in the perception model very often stem from an impoverished understanding of what actually takes place in perception. Nevertheless, just as perception can be embedded into a wider range of reciprocal potential, so desire is another aspect of openness to the world that reveals important processes of valuation if it is similarly embedded into an ecological understanding. ${ }^{12}$ It is not a question of having to choose between "models" of valuation here (any more than human life is a matter of having to choose between perceiving and desiring). Rather, it is a matter of reinscribing these capacities into the full range of our valuative opening and taking of the world.

So, perception and desire serve, roughly, as objects of comparison in Wittgenstein's sense. ${ }^{13}$ We can learn more about where value "resides" from their various kinds of appropriateness and their limitations. Just as a perceptual model can risk missing the active, process-based and relational dimensions of value and valuation, so a desire-based "model" has its limitations too, as we now show.

John Dewey offers a classic statement of the "desire" model of valuation. For Dewey, it is important both to see the distinction between what he calls "prizing" and "appraising," 14 or between valuation and evaluation, and also to see that these are not experientially separable phenomena. "Prizing" is the basis of all valuing and is not itself evaluative; it is not the measuring of one thing/situation/possibility against another. Nevertheless, one must continually appraise one's situation. Prizing and appraising are practically inseparable and mutually conditioning activities. ${ }^{15}$ For Dewey, prizing and appraisal are to be understood in terms of desire and interest, but desires and interests are not ultimate givens. This is because valuations arise out of situations when those situations or those experiencing them are threatened, disrupted or felt to be lacking in some way. Desires and interests are only fully

practice, not as a final once-and-for-all judgment of what it will be most therapeutic to say.

${ }^{11}$ See Ingmar Persson, "The Desire Relativity of Value," in The Retreat of Reason: A Dilemma in the Philosophy of Life (Oxford: Oxford University Press, 2005), pp. 143-57.

12 Ted Toadvine attempts something similar in "The Primacy of Desire and its Ecological Consequences," in Eco-Phenomenology: Back to the Earth Itself, ed. Charles S. Brown and Ted Toadvine (Albany: State University of New York Press, 2003), pp. 139-53. However, his attempt to deploy Schopenhauer's notion of the will for this purpose seems fated to cause more confusion than it is worth.

${ }^{13}$ Cf. Wittgenstein's Philosophical Investigations (London: MacMillan, 2009), secs. 130-32.

${ }^{14}$ John Dewey, Theory of Valuation, in Foundations of the Unity of Science, vol. 2, no. 4 (Chicago: University of Chicago Press, 1939), p. 5. Following this terminology we use valuation throughout this article to refer to the basic events through which anything comes to be valuable. The term valuation used by economists to designate the process of weighing relative values against one another would, in this terminology, be designated as "evaluation."

15 Joel Kovel makes a similar conceptual distinction, and claim for experiential inseparability, in Marxian terms. Kovel reads Marx as claiming that "use-value is embedded in natural ecologies, but at the same time, he sees no need to differentiate use-value from any notion of intrinsic value in nature." 
formed in the process of valuation that in each case concretely tackles the situational inadequacy.

This has the effect of shifting one's focus from what might be taken as a purely "subjective" attitudinal stance, toward the situation as itself the ongoing event of evaluation. However, this strategy carries with it a subtle risk. It has the effect of situating Dewey's understanding of desire within the tradition that sees at the heart of desire a lack that we desire/"need" to fill. Desire thought in these terms is in danger of setting up the desired "situation" as a fully actualizable state of complete fulfilment in which there would be no more desire. Yet there is no situation of repletion in which desire would be overcome as such; or at least, the idea of fulfilling desires as a general means of eliminating them is a hopeless one.

There is then a serious risk that we will seek fulfilment in the perpetually and continually augmented process of appraisal, desire, and exploitation. This is a recipe for the kind of futile dissatisfaction inherent in cycles of advertising and consumption. We desire the full actualisation of a particular state of affairs or the complete availability of a particular range of products that nature can provide us with, e.g., the reduction of natural beings to a narrowly defined set of resource providers: hens become egg- and meat-production units (eggs and flesh being desired for their taste and nutritional qualities), rivers and waves become electricity production units, etc., and these are all put into the service of (human) "desire-satisfaction." Thus Deweyan desire-based evaluation, for all the soundness of some of its founding insights (viz., the distinction between prizing and appraising and their practical inseparability), cannot by itself possibly be an adequate basis for an ecological ethic, for it is complicit with a kind of "deep consumerism" and a conversion of what we want into resources.

Once more, we do not need to replace thinking about valuation in terms of desire, but to embed desire in a broader openness to the lived world. Desire becomes enriched, sublated, transformed, when it is no longer the desire for a state of affairs in which the desired object is placed fully at one's disposal. Such desire and its satisfaction, as one knows all too well from reflecting upon consumerism, ${ }^{16}$ is ultimately self-frustrating, unfulfillable. However, if instead we think of desire as taking place within an ongoing event of caring, such as for instance of someone caring for somebody who has been injured or is ill, in which we foster a wide range of potential in those involved, including those of the care givers, in bringing about the healing that is desired, ${ }^{17}$ then the narrow and ultimately self-frustrating desire

\footnotetext{
Joel Kovel, The Enemy of Nature, 1st ed. (London: Zed Books, 2002), n. 28, p. 223.

${ }^{16}$ It is worth noting that consumerism of course doesn't actually give us what we desire. It merely tempts us to think it is doing so. This itself demonstrates our point: our true desire, desire sublated from its surface form as satisfiable by some manipulation of nature, can transcend the kind of phantasm of desire-unleashed that consumerism manifests.

${ }^{17}$ Dewey maintains a certain dogmatic humanist cognitivism when it comes to the recognition of all "carings-for" as valuations. As Paul Ott points out, he denies that any animal "carings-for" can count
} 
for the complete availability of some particular potencies and products that one has fixated upon can start to lose its grip.

If, furthermore, the caring-for and fostering of potential in and for others takes place as an experience of opening the world in love, then the self-frustrating and enclosing tendencies of bare desires are drawn beyond themselves. Isolated "carings-for" are understood in context as part of an ongoing fostering of potential. Concrete potential does not always have to be fostered with a view to its complete actualisation in order to be prized. We can foster potential and possibilities for those we love without demanding that every possibility we foster together is fully realized. For example, one can foster the love of music, without demanding that those in/for whom we foster it realize any specific musical talent. We love other human beings, but we also love all sorts of living beings, bio-physical systems and the Earth. Moreover, we are loved by other beings, even and sometimes even perhaps especially when we do not realize it.

Roughly speaking, then, value resides in the mutual and reciprocal fostering of shared possibilities of the world and only then in the actual (perceived) configurations of that world and the qualities of things that become the objects of desire and utility.

\section{WHAT MAKES VALUING POSSIBLE AND WHAT VALUING MAKES POSSIBLE}

Having shown some of the advantages and some of the limitations of these two "models" of valuation considered in the previous two parts, we now give an account of the conditions of valuation that make up our own ecological "model." This account necessarily involves showing how valuations take place in relational ecological being-with-others and in the midst of the natural world.

Open-ended openness, the openness of humans and some other living beings to the world, has various dimensions, including perception and desire, which can thus become significant "models" for valuation but should not be taken as the only capabilities that make valuation possible. On the contrary, we humans are not entitled to regard ourselves as the measure of the world. Nor should we claim, as Heidegger notoriously seemed to claim, that other creatures are necessarily "poor-in-world," at least if this is taken to mean that they are negatively evaluated, homogenous in their ways of relating to their worlds, or that they inhabit worlds that are simple

\footnotetext{
as valuations because he claims that they do not involve foresight and purposiveness, and so cannot become the reasons for caring. Paul Ott, "Value as Practice and the Practice of Value: Dewey's Value Theory for Environmental Ethics' Environmental Ethics 32 (2010): 292. Not only is this quite possibly false in various cases (among various "higher" animals - see below), it misses the way in which all of these carings-for allow us all along-with-one-another, human and "more/other than" human, to remain open to a valuable world. For more on animals human-and-otherwise in the context of Dewey and Wittgenstein, see Rupert Read's "Nature, Culture, Ecosystem," in his Philosophy for Life (London:
} 
and self-contained. Heidegger's claim has frequently been taken in such ways, not entirely without justification. ${ }^{18}$

Every living being that is in some way or to some degree open to the world has, one might say, its own world, its own set of Gibsonian "affordances," its own capacity to find valuable. ${ }^{19}$ Open-endedly open beings create an ecological community of valuers through their capacity to be open not only to their own world and to the worlds of others, but also to the open-ended potential for possible affordances and encounters between living beings and their worlds.

It might at this point be objected that our definition of "open-endedly open" is less precise than is generally preferred in philosophy. This is inevitable in this case. The concept indicates a limit to what can be specified in advance. The idea reflects a resistance to the thought that there are stable and isolable affordances.

Open-endedly open beings are de-centered, so that they can experience the intersecting environments of other living beings in a way well illustrated in the following passage:

Every animal and every species of animal actively encircles itself in its own way with [an] encircling ring, with which it circumscribes and adapts itself to a certain domain. The ring that encircles the sea-urchin is quite different from that of the bee, and that of the bee quite different again from that of the great tit, and this different from that of the squirrel and so on. But these encircling rings belonging to the animals, within which their contextual behavior and instinctual activity moves, are not simply laid down alongside or in between one another but rather intersect one another. The woodworm, for example, that bores into the bark of the oak tree is encircled by its own specific ring. But the woodworm itself, and that means together with this encircling ring of its own, finds itself in turn within the ring encircling the woodpecker as it looks for the worm. And this woodpecker finds in all this within the ring that encircles the squirrel that startles it as it works. Now this whole context of openness within the rings of captivation encircling the animal realm is not merely characterised by an enormous

Continuum, 2007).

${ }^{18}$ For readings that highlight the potential problems, see Jacques Derrida, Of Spirit: Heidegger and the Question, trans. Geoffrey Bennington and Rachel Bowlby (Chicago: University of Chicago Press, 1989); David Farrell Krell, Daimon Life: Heidegger and Life-Philosophy (Bloomington: Indiana University Press, 1992); On Being with Others: Heidegger-Derrida-Wittgenstein (London: Routledge, 1998), and Alistair MacIntyre, Dependent Rational Animals (London: Duckworth, 1999). For alternative readings that suggest possibilities that we build upon in what follows, see Tom Greaves, "The Word's Silent Spring: Heidegger and Herder on Animality and the Origin of Language," in Heidegger and the Earth: Essays in Environmental Philosophy, 2nd ed. and enl., ed. Ladelle McWhorter and Gail Stenstad (Toronto: Toronto University Press, 2009) 103-22, and William McNeill, The Time of Life: Heidegger and Ethos (Albany: State University of New York Press, 2006).

${ }^{19}$ Several scholars have recently made the connection between Gibson's concept and the ideas of Jakob von Uexküll and Martin Heidegger that we explore below. They remain divided, however, on the issue of whether Gibson makes a real break from the subject/object dichotomy. See Tim Ingold, Being Alive: Essays on Movement, Knowledge and Description (London and New York: Routledge, 2011) chap. 6, and Vincent Blok "Reconnecting with Nature in the Age of Technology: The Heidegger and 
wealth of contents and relations which we can hardly imagine, but in all this it is still fundamentally different from the manifestness of beings as encountered in the worldforming Dasein of man. ${ }^{20}$

The reason for that is that the specific "transposedness" of Dasein is the de-centred openness through which finds itself in the midst of this multiplicity of intersecting worlds. Animals are open to their environments, but, Heidegger claims, not to the "context of openness" itself that they are moving and behaving within. Though we remain concerned that in the final sentence of this quotation Heidegger closes off the crucial possibility that nonhuman animals too may partake of Dasein. ${ }^{21}$ The underlying thought is that living beings are nothing more or less than the constant co-constituting forming and reforming of themselves, one another, and their environing fields of potential. Only some of the capacities formed in this way are capacities for awareness. Whatever comes to be encompassed by these intersecting rings can have value, both because it can be essential to the existence of valuers and the valued, and because it can itself be the object of a meaningful valuing.

One speaks glibly of "the nonhuman world," but this expression runs together a whole panoply of worlds and rings, and thereby two different senses of the word "world." Beings that are open-endedly open must be beings that understand that there are other open beings. We are confident that primates and cetaceans are such beings, and that to some extent many other animals besides may be. Beings that do not have any sense that there are other open beings are the only beings that could be called "poor-in-world." Even then one has to take great care, for they gain something as well as losing something by virtue of being thoroughly immersed in their environing ring.

In the sense in which Heidegger tends to use the word world, then, each creature with some degree of open-ended openness has for us a world. The term the nonhuman world is not used in this sense. The nonhuman world contains the world of the spider, the world of the shark, the world of the mouse: and many of these are or may be another world, though they also, and this is critically important, intersect as Heidegger rightly points out. Our view is that the intersection is also a co-constitution, since, as we have already indicated, all of these living beings become what they are within the ecological field that open-ended openness makes possible. Without

Radical Environmentalsim Debate Revisited," in Environmental Philosophy 11, no. 2 (2014): 307-32.

${ }^{20}$ Martin Heidegger, The Fundamental Concepts of Metaphysics trans. William McNeill and Nicholas Walker (Bloomington: Indiana University Press 1995), p. 277. Cf. also p.141 of Katherine Morris's Starting with Merleau-Ponty (London: Continuum, 2012), where she writes: "[Jacob von Uexkull's great contribution was to develop the notion of environment (Umwelt), which he described as the sum of the "perception world" (Merkwelt) and the 'effect world' (Wirkwelt-i.e., the world of acting or doing) and which varied from species to species, so that each animal has its own world." We emphasize, as Heidegger does, the intersection and co-constitution of these worlds, which makes a further, crucial difference

${ }^{21}$ On this point, cf. Merleau-Ponty's seeming to allow, as we certainly wish to, on pp. 125-26 of The Structure of Behavior (Boston: Beacon Press, 1963), that some nonhuman animals are (or at least 
the latter, there would be intersection and thus specific co-constitutions but not a field of actual and potential intersections where valuation takes place.

From the point of view of the spider, the material of the human world is just another part of "the non-spider world" (understanding that term by analogy with the way the term the nonhuman world is used by us humans): though the spider probably lacks a world itself. From the point of view of the gorilla, the human world is at least to some extent another world (though gorillas may well have much greater difficulty even than us in ascertaining just how very different that world is). Others' worlds or environing rings are different from ours, and not to be assessed simply by reference to ours, though (crucially) they help constitute ours. They are not to be measured by ours. Humans are not the measure of all animals. ${ }^{22}$

While openness to the world is required for values to be, we certainly must not conclude from this that only beings with the widest range of capabilities are valuable. Nor should we conclude that only those beings that are directly involved in the opening of the world in at least some minimal way are valuable. It is not that certain distinct things are valuable simply because we make those things valuable by relating them to ourselves. Rather, ecological value is made possible in the world that is perceived or can be perceived and cared for ${ }^{23}$ on the condition that a multitude of beings are open to that world in a multiplicity of ways and forms, including some that are, as we term it, more or less open-endedly open.

When we "open the world" along with one another we perceive that world and care for it. ${ }^{24}$ Together we can see the value in each thing in ways that would not be possible if we were not open to the world and some of us were not open-endedly open. The "us" now should include some nonhuman animals, with their own "worlds."

Within the broadly ecological condition of valuation that we are developing, certain special conditions for valuation can be discerned. Anything other than

\section{can be) Dasein.}

22 One might want to draw some (always tentative and unclear) lines between (a) worldhood that includes reflection (that is thus clearly to some degree open-endedly open); (b) worldhood that does not involve any reflection (such worldhood is open, but not open-endedly so); (c) poverty in world, when we encounter living beings and remain at best ambiguous about whether they have a world; (d) beings (if that is even the right word) that clearly lack a world. It should be emphasized that the drawing of such lines, even tentatively, may be problematic, since it might lead us away from noticing the radical differences between things in each "group," and the ways in which members of group each generally miss out on some features of/capabilities of members of other groups.

${ }^{23}$ Grounding for this emphasis on love, which may surprise some readers more used to a focus on justice, can be found in Read's “Love or Justice?" (http://www.greenhousethinktank.org/files/greenhouse/ admin/How_ought_we_to_think_of_our_relationship_to_future_generations.doc).

${ }^{24}$ It should be noted that once there are some beings with open-ended openness involved, the capacities and potential that make for different kinds of valuation do not strictly speaking belong to one being or another involved in that valuation. They are, rather, capacities brought about by all. This is a key flaw with existing conceptions of sentience that regards the matter as being settled by attention to each species individually. Rather, it is in the differences that can be made by members of one species' attention to members of another that the really radical effect of the overlapping of different creatures' 
relatively open-endedly open beings cannot unmetaphorically be said to have an interest in anything.

Do trees take an interest in anything? Do they have an interest in not being cut down? We suspect not, at least in the cognitive sense of the word interest. However, it might well make sense to say they do in their being along with all the openendedly open beings living in and around them - it is not just our interest, but the tree-along-with-all-in-and-around the tree, that might speak against the tree being cut down. We are implying then a sense in which the term interest may be able to escape the dualism of being understood in terms of a life that is understood by the liver (interest in the cognitive sense) or that is not (interest simply in the vital sense). We are suggesting the transcendence of the individual being.

Do rocks take an interest in not being pulverised? No, because they don't have interests in anything at all: they lack not only cognitive but vital interest, for the simple reason that they are not alive. Sentience is being open to what is actually and potentially there. ${ }^{25}$

If the white cliffs of Dover or the Amazon rain forest are under threat, then something valuable is under threat. That doesn't mean that what is valuable has to have interests or sentience, and nor does it even mean that it has to contain beings that do (although, of course, the Amazon rain forest very obviously does, as indeed do the white cliffs of Dover). Recognizing this profound value does not require us to attribute human-like/animal-like qualities to trees. It is more than individuals that are valuable (and thus - and we will return to this point in the following section - it is clear that Peter Singer's famous view that only individual sentient beings have value is wrong ${ }^{26}$ ).

Compare in the context of this line of thought the following important remark of Wittgenstein's, from his anti-“private-language" considerations:

Look at a stone and imagine it having sensation. - One says to oneself: How could one so much as get the idea of ascribing a sensation to a thing? One might as well ascribe it to a number!-And now look at a wriggling fly and at once these difficulties vanish and pain seems able to get a foothold here, where before everything was, so to speak, too smooth for it." 27

Sentience yields a foothold of value on the smoothest rockface, once there are open beings to live on or with it. The wriggling fly, in its being contemplated, is part of an ecological field of full richness.

Thus, there is in most cases no question about whether rocks - such as a cliff, a

worlds is to be found.

${ }^{25}$ Notice, crucially, that this is a very broad rendition of "sentience." Sentience in this sense might conceivably go as far as the limits of life itself. It will certainly penetrate rather further into the animal world than is usually acknowledged. We expand on this point in the opening of sec. 5 below.

${ }^{26}$ This claim of Singer's was first made in his 1974 paper, "All Animals are Equal," Philosophical Exchange 1. Reprinted in Hugh LaFollette, ed., Ethics in Practice, 3rd ed. (Malden, Mass.: Blackwell, 2007), pp. 171-80, esp. p. 175. 
rockface, or some ancient ruins have value: they clearly do. Nor is there any question about whether trees - which do not wriggle - have value; they are valuable in a multitude of ways, many of which have nothing whatsoever to do with the production of timber. When we ask the question of whether trees have the kind of being that serves or could serve as the essential condition for valuation we are tempted to conduct what may be subtly untenable thought experiments. If trees were the only living beings on Earth, would anything have value? Could trees alone bring about valuation? Quite apart from the important fact that trees could almost certainly not be the sole living inhabitants of this Earth, one does not entirely succeed in imagining this scenario because the very imagining is essentially conditioned upon our very own kind of being and cannot be left behind when we try to imagine the earth thus. What we can perhaps do is to imagine a world of trees and then try to think of them quite apart from any kind of value that they can have for us. Is there any kind of value left that is simply value for them? Can we perhaps be transposed, even if only with great effort and quite inadequately, into the life world of a tree? This seems difficult, for it would go far beyond simply asking oneself, "If I were that tree, what would I think or feel in this situation," where I basically think about how I would feel as a human being deprived of water, strangled by ivy, deprived of a limb, etc. When we try to enter the "life world" of the tree, we see that the valuations (if any) that we are exposed to in doing so would be quite thoroughly distinct from those that we are used to. (If a tree were to speak, we certainly could not understand it. . . .) Can I begin to experience being alive in such a way that "losing a limb" means something quite profoundly different to (crucially, "less" than) losing a limb as a human animal?

If I marvel at a rock formation or puzzle at a set of numbers then valuations can take place, but of quite different kinds to those that are possible when we try to transpose ourselves into the worlds of other living beings, including possibly plants.

Let us return to the distinction between interest and value. Why should "interests" only be ascribed to those who can feel sensations, whether a fly or a fish or a human being? Because something that has no sentience at all can take no interest in anything. Taking an interest (thus, "interest" in the cognitive sense) in something involves a direction of attention, and often a struggle. As we have tried to show, there is no "bare sensation," but only sensation as it is lived in a world. Only sensation that affords, and is afforded. The (still open) question of a tree's putative worldhood is also a question of what we are prepared in each encounter and each context to ascribe to the tree. A tree does not seem to have a direction of attention or to pursue any kind of directed struggle, although this cannot be entirely ruled out. ${ }^{28}$ But trees

\footnotetext{
27 Wittgenstein, Philosophical Investigations, par. 284 (emphasis added).

${ }^{28}$ They struggle for light, etc., and this is not just a mechanical reaction. See in this connection the provocative argument of Michael Marder that vegetal life involves non-conscious intentionality and even existentiality that is nevertheless not "directed" in the same way as that of animal life. Michael Marder, Plant Thinking: A Philosophy of Vegetal Life (New York: Columbia University Press, 2013).
} 
surely can't suffer in anything much like the ordinary sense of that term. Suffering is a crucial constraint and the minimization of any suffering imposed by us is a significant goal. It needs to be treated as one crucial aspect of what we do when we value. Plants and microbes appear to feature in it only indirectly, not directly.

Anyone who supposes or argues that trees and microbes and even (non-living things such as) rocks and valleys have interests may well be doing so, we suggest, because they feel intuitively that these things have value; because they cannot see how to attribute value without attributing interests. We are arguing against this equation of value and interests. (We are suggesting that having an individualisable cognitive interest or even vital interest is not a sine qua non for having value.)

Or possibly these philosophers argue thus because they think people only take the interests of others seriously when they think of those others as slightly extended and altered versions of themselves. A kind of subtle prosthetic perhaps. This is not so (or at least: it is not true of $u s$, qua philosophers!). In order to really appreciate nature, we have to be willing (and we often are, already) to encounter its difference. Philosophers who have sought to ascribe interests to the non-animal world are in the game of not making different enough. ${ }^{29}$ They pretend that all of nature is just like us; being unwilling to consider finding value in the deeply different. We hold that our care for nature has a different basis than just the hopeless and counter-productive attempt to figure nature as more of the same.

There is not a complete all-purpose union between "us" and "them," in the cases of rivers, trees, other animals, nor a feasible modelling of them directly on us. And yet: to an important degree, we are them and they are us.

It is not that we come to find nature as being humanity-in-disguise; rather, we come to find that we can, and indeed already do, value what is not ourselves; at least, as we had previously thought of ourselves. ${ }^{30}$

\section{CONCLUSION}

Our argument has proceeded to a considerable extent by means of examining the "status" of animals and of other beings that may well appear to lack the openness of many animals. We have thus in practice suggested above a reason for thinking that influential thinkers such as Peter Singer are roughly right, albeit for some of the wrong reasons, about the ungainsayable importance of sensation, of sentience, including

\footnotetext{
${ }^{29}$ We are thinking here of Wittgenstein's fundamental philosophical attitude, as manifested for instance in the line from King Lear ("I'll teach you differences") that he took as a motto for Philosophical Investigations; and in par. 339, as in many other passages. Gaia theory (and some of the contemporary talk of "Mother Earth") risks being a classic example of "not making different enough": of trying to model the entire Earth system too much on ourselves, on organisms, as if we couldn't care for the Earth without seeing it as literally alive. See again chapter one of Read's Philosophy for Life.

${ }^{30}$ For we can undergo a change of perspective that can make visible for us a new aspect, in which the rivers, the Earth itself, are us: this is what Joanna Macy undertakes and offers, in World as Lover, World as Self (http://www.context.org/iclib/ic34/macy).
} 
of suffering, for the concept of (anything like) cognitive interest: some degree of such openness is certainly required, in order for one to be confident that (say) a tree is of value. ${ }^{31}$ However, while we have also sought to point out the importance of a version of openness - open-ended openness - that is less widespread, if there is truly to be a "community," in the natural world, we have also sought to balance this with a determined resistance to the temptation toward anthropocentrism that such a realization can foster (and perhaps did, in Heidegger), whereas Singer has, ironically (for the so-called father of "animal liberation"), highly anthropocentric notions of sentience, pain, and suffering. There might be suffering that is very unlike the kind of suffering that humans can experience. When we use the term sentience, unlike Singer, we mean initially only the ability to sense in any of a multiplicity of ways. This is enough for the possibility of world, and it may well be enough also for the possibility of something resembling suffering to gain a foothold. ${ }^{32}$

Singer is, however, just wrong about the concept of value. This is a key point that we have aimed to establish in the present piece, by placing value appositely in its proper ecology. Value depends on sentience (in the sense simply that there is no value in the total absence of sentience, if we can even get as far as imagining that). Value is conditioned upon sentience, sensing and suffering within the world and acting within the world, and there is no thinking of world without open-endedly open being; but what is valuable is absolutely not reducible to sentience and interests. Rather, value is least-problematically said to be found in the interstices between the "valuer(s)" and the "valued." Initial appearances notwithstanding, this relationship is not one-way or one-sided.

So anthropocentrism is simply wrong, given the presence on this Earth of nonhumam animals. Humans are not the only source of valuation. But even if they were, it would still be a profound mistake to think that only what is a source of valuation is itself valuable. We, and members of the ecological community at large, value all kinds of things in all kinds of ways. These things (that are in many cases of course precisely not "things") have value.

As Wittgensteinian philosophy teaches, value is not an object, no matter of what sort, just because it is a noun. Values aren't things. This is why we have sought to focus attention onto the processual, active and eventive aspects of valuing. It is not something done by an atomized individual subject, but an event process in which we all take part or have a part, like it or not: value as "between.",33

The ecological conception of valuation entails that neither the conditions nor the bearers of value have stable, specifiable, locations. They are widespread and

\footnotetext{
${ }^{31}$ We would argue that this is true of rights, although as a utilitarian Singer would not agree. As Gary L. Francione argues, this entails that we are absolutely not able to reduce animals to property (see e.g., his Animals, Property and the Law [Philadelphia: Temple, 1995]).

${ }^{32}$ See again the passage from Wittgenstein, Philosophical Investigations, par. 284 cited above.

${ }^{33}$ See especially the opening chapters, and chap. 4, of Iain McGilchrist's The Master and his Emissary (New Haven: Yale University Press, 2009), for illuminating discussion of the notion of "betweenness" as essential to a proper understanding of valuation.
} 
ever-changing. What we have suggested here is that value depends on open-endedly open beings who necessarily reside in the world, that is, on the Earth (and in the earth, in the air, in the sea ...). Yet value itself is far more "widespread." It does not really reside anywhere finally specifiable. Value, we have suggested, is a series of endlessly ongoing and fluxing "events." It is a process that we must play an active and embodied part in. This activity must not be construed anti-realistically/subjectivistically. ${ }^{34}$ We need to think evaluation rather, perhaps, as "active passivity." We need to find a "middle voice" for it, beyond objectivism and subjectivism. ${ }^{35}$ As for instance in the Alexander Technique, beloved of John Dewey; rather than doing back exercises, one simply allows one's back to lengthen and stretch. Yet there has to be a doing (and a being) that enables this non-doing to take place.

As we argued in section four, sentience is being open to what is actually and potentially there. We need openness to what can be-relations to other living beings ("even" plants, of course, because we only engage with the tree as tree when we engage with its potencies, which are not simply "natural ends" set in it from the start, because they depend on how it comes to "relate" to (to co-constitute) its whole "environment") can help us here, and can even enable us to be open in this way.

What, then, is valuable? The Earth, life, beauty in nature and art, a vast multiplicity of things, many of which we are only vaguely aware of or not even actually aware at all as yet. Value "resides" in these "things," 36 but it requires us open-endedly open beings as its potential witnesses. Witnesses in the sense roughly of witnesses at a wedding. "Witnessing" is the kind of "active passivity" we referred to above.

It is sufficient for there to be subjective value that there be openness. For genuinely ecological value to be possible, for the myriad of things that are valuable to be valuable, some open-ended openness is required. That is the distinctive contribution of humans and other "higher" animals. That is the wonderful outcome of our collective "witnessing."

In making these claims we have not moved magically to some "meta-ethical" realm or cool place; there is no escape from substantive valuation. When we remark on where value "resides," this is a claim we are making. It is an act we are carrying out (in this case, a linguistic act). It is part of the process that we have described in

\footnotetext{
${ }^{34} \mathrm{McDowell}$ is once more useful here. See especially his article in Alice Crary and Rupert Read, eds., The New Witttgenstein (London: Routledge, 2000).

${ }^{35}$ The best discussion of the notion of "middle-voice" as an activity-receptivity essential for ecological responsibility remains John Llewelyn's magnificent The Middle Voice of Ecological Conscience: A Chiasmic Reading of Responsibility in the Neighbourhood of Levinas, Heidegger and Others (Houndsmill: MacMillan, 1991)

${ }^{36}$ And here the reader can see the full sense in which we mean to be speaking of "ecological value." As intimated at the opening of this paper, we aim to understand value in its ecology; our thought is in part that value needs to be understood "ecologically" both in the sense of: in relation to the natural world; and in the sense of in its proper place and context, where it lives, where it thrives (this sense of the term ecology is once more as in James Gibson's ecological approach to visual perception, etc.). We think that these turn out to be the same thing....
} 
the present paper as what value is. It is part of that event, or one such event. Value resides, one might say, everywhere; including right here in these thoughts and in what, we hope, may follow from them.

\section{FRAGMENTS OF A "CASE STUDY"}

What comes after a conclusion? Putting it to work. We want to show that what we have argued above can be put to work. So we close with the schematic outline of a case study. In the following pages, we briefly outline a critique of the increasingly influential "TEEB" ("The Economics of Ecosystems and Biodiversity") approach to valuing life. We think that the way we have sought to re-present valuing sheds light on some damaging tacit philosophical presumptions in the mainstream discourse now accumulating around "biodiversity."

We take as our text the influential "TEEB for National or International Policy Makers" document. ${ }^{37}$ Let us begin with a couple of early warning signs. We are told up front in this document that "around one European job in every six is somehow dependent on the environment." 38 An adequate understanding of the word environment, especially when the claim qualified by "somehow" suggests that the figure should actually be: six jobs in every six. . . . The slip is revealing of the extent to which this "ecosystem-based" approach is still tacitly figuring the Earth as a resource and an "externality" to the "real" economy. Its being and its value is then bound to be instrumentally conceived, not something to which we are internally related. To sum up this point, conceiving of nature as external to us is a bad mistake.

The TEEB regards "biological resources [as] a stock of capital in their own right." ${ }^{39}$ But this is still problematic. Using "capital" as one's founding metaphor already implicitly figures nature as something to be placed under an economic system of measure. Biological resources become a kind of capital. We assume that we know everything that there is to know about capital, and that we can then carry that over directly to refigure nature. Nature is then placed essentially under the "law table" of human beings and our economics. Any sense of otherness, or of "intrinsicness," or even of betweenness, is already over once this move has been made. To sum up this point, thinking of nature as "internal" to $u s-$ i.e., internalizing it within the human economy - risks being just as bad, just as deep a mistake, as thinking of it as "external." It risks figuring ecology as just another extended version of that economy. The mistakes of externalisation and internalization display the same failure to think of an ecological community of difference where valuation takes place between the different members.

Here is a particularly striking example of the consequences. In the course of

\footnotetext{
37 "TEEB - The Economics of Ecosystems and Biodiversity for Nationa and International Policy Makers-Summary: Responding to the Value of Nature" (2009) (http://ec.europa.eu/environment/ nature/biodiversity/economics/pdf/d1_summary.pdf).

${ }^{38}$ Ibid., p. 24.

${ }^{39}$ Ibid., p. 14.
} 
a discussion of the economic value of coral reefs, we read the following: "Coral reefs are now understood to have a critical range of ecosystem service values - for natural hazard management ..., tourism . .., genetic materials and bio-prospecting ... , fisheries. . . . These benefits are site-specific-so a global loss of coral reefs will impact communities differently. Lost benefits will be lowest in places with few people, poor ecosystem quality or limited accessibility. . . . The lowest values generally correspond to sites with limited accessibility or facilities for tourism, while the very high values relate to international tourism hotspots." 40 Coral reefs with limited accessibility are less valuable than those on the tourist trail. There is no room here, it seems, for the idea that we might rightly value coral reefs that are inaccessible to us more than those that are accessible. That the less accessible reefs might, through being less accessible, be more valuable and/or valuable in a quite different way. If I value some remote part of the Great Barrier Reef or the Queensland rain forest, that does not necessarily mean that I will want be in that reef or forest or as close to it as possible, for as much of my life as possible. It may be that I value it by not going into it at all. I might value it precisely as wild nature. It may even be of value through not being part of any active focussed present prizing by me or anyone else (In other words: I might well value precisely that there are things that I don't put any first-order value on. . . . We can escape the seeming-limit of whatever we value seemingly being of value only in virtue of being prized by us.). So long as it is encompassed by the co-constituting worlds of living beings, feeding in some way or another into their potential, it can be valuable even if none are aware of that value or even if it is not the kind of thing that they could become aware of as individuals.

Of course, the very concept of "ecosystem services," central to TEEB, and explicit in the quotation given above, is itself deeply troubling. It figures the planet as a source of services to us, the ultimate "service provider." One that does not even need to be paid for, since any money that changes hands necessarily goes to humans: to governments, corporations, etc. . . Once one questions the concept of "ecosystem services," one has to question the very idea of TEEB.

Similar concerns could be raised with regard to other currently influential projects for "valuing biodiversity." For example, there are clearly things to welcome in the massive, newly publicized NERC project, "Valuing Nature" 41 including the remarks of its principal investigator, our colleague Ian Bateman, to the effect that the value of nature is, strictly speaking, infinite. ${ }^{42}$ What Bateman says on this score is far less troubling than the claim of Costanza et al. that a price tag can notionally be put on the whole of nature, in terms of the "ecosystem services" it delivers.

\footnotetext{
40 Ibid., p. 11.
}

41 "Valuing Nature" (http://www.valuing-nature.net).

42 See http://www.ft.com/cms/s/2/644b1884-8c7c-11e0-883f-00144feab49a.html\#axzz1O6Gtm2d6 and http://www.bbc.co.uk/news/science-environment-13616543. Ian Bateman's stance is thus better than the available alternatives, to date. But we want to look toward something post-NERC (and postTEEB) that would actually be: good enough. "Intrinsic value" will always lose in the balance if it is

add referemce for Constanza et al. 
Yet it is troubling that Bateman nevertheless refuses to consider the possibility of nature having (as he puts it) "intrinsic value." He defends this refusal with the argument that we cannot know if we are valuing nature as it itself (or they themselves, in the case of nonhuman animals) would want to be valued. ${ }^{43}$ How do we know what a whale values, Bateman asks, rhetorically? This is somewhat ironic as a dogmatic assertion (that we do not, and so cannot ascribe them any "intrinsic" value) made in the course of an investigation into the value of nature, since when it comes to assessing the values held dear by human beings we are frequently reminded that behavior is usually a far better indicator of "preference" than the explicit claims that people make. In other words: advocates of CBA and/or RCT have particularly little ground to stand on, in resisting the idea that the preferences/ values of nonhuman animals need to be taken seriously. Similarly, we can look and see what a whale values. Their preferences are revealed by their actions.

It is particularly ironic that Bateman picks on whales - for whales are surely not merely open, but manifest some open-ended openness. In their capacity for instance for communicative song, song that exhibits development and regional/"tribal"/personal variation, they appear to be, subtly, growing ecological valuers. We humans have a very great deal still to learn about whales; they sound in love with each other, or with their world.

Even if this weren't the case, Bateman's rhetorical question is in any case making the classic move that we diagnosed and critiqued earlier in the present paper. He moves smoothly from something not necessarily being valued by " $u s$ " to its not being of value. Whereas value requires ecological valuers as its condition, but is by no means exhausted by that condition.

the intrinsic value of (e.g.) a forest, something nonhuman. Instrumentalist CBA must be rejected/ transcended, because of incommensurability (because of the reality of the infinite value of life, of the whole of nature, though our perspective in the present paper also puts into question whether it can really make sense to "sum' the whole of nature, at all. . .). We are trying to offer the schematic beginning of a viable alternative that could find its way eventually into a policy document that would transcend the TEEB (and the NERC work of Bateman et al.), an alternative that would be based on "placing" value itself between. And doing so would thus overcome the dubious meaning that the term environment has come to have, of something "out there" to be "managed," and would midwife a recovery of the earlier, better, encompassing, more "ecological" sense of the term environment, a sense that is to some degree already afforded by the gap-dissolving concept of "affordances."

${ }^{43}$ Bateman's argument (presented at the University of East Anglia on 31 March 2011) is reminiscent of the argument currently, tragically, being used to justify the destruction of the world's greatest seed bank, which in older, perhaps better days scientists died of starvation rather than consuming (see http://www.care2. com/causes/real-food/blog/historic-russian-seed-bank-faces-destruction), in Moscow: "Under [a] mindboggling quirk, the fact that the land is deemed as 'priceless' also gives developers a right to build there. 'To legally prove that we are using these lands, we need to put a value on the collection which is impossible. There are no methods for that. How can we put a price on a collection that is unique and only exists here""' (http://www.expatica.ru/news/news_focus/Outrage-as-priceless-Russian-seed-bankfaces-destruction_92206.html). "Priceless" becomes equated with valueless. This is an obscene turning on its head of our system of value. 
If our argument is right, the truth that trees don't suffer as we do and the (far smaller) element of truth there might be in the claim that there is something potentially problematic in ascriptions of interests to whales (for we submit that difficulties in understanding what exactly it is like to be a whale do not gainsay that whales clearly have not only vital but also cognitive interests, and that they join us in (helping to constitute!) a community of open-endedly open beings) does not in any case in any way license Bateman's refusal to countenance intrinsic value. Rather, we need to be open to the different kinds of value that are to be found in living alongside and among living beings other than ourselves. Just because this value cannot be assessed in the terms that one is used to nor even in further broadenings of those terms (the kind of broadening found for instance in Costanzian "ecological" economics, which the TEEB and NERC projects are inheritors of) does not imply that it simply cannot or should not be talked about or taken seriously. On the contrary, it gives us all the greater responsibility for taking it seriously. We need to ensure precisely that there is space for the value of what and where we are not. Value lies between us, between us and where we are not. It cannot and must not be pulled back onto and into us alone. This is true, we have suggested, regardless of the extent to which we understand other beings.

Perhaps Bateman and others thinking similarly to him are caught up in the allegedly stark opposition of intrinsic to instrumental value. Our suggestion has been that the old saw of environmental ethics, "intrinsic value," is better understood as or changed into a between than as inhering solely and fully in other things (That is, we need to transcend the dichotomy of nature as either "external" to us or "internal" to us). Every "instrumental" value requires something "intrinsic" to "measure" it by and every intrinsic value that we are open to must be appraised in practice. Our own value is inextricable from the value of that around us. The valuations of non-human animals are values that are to some significant extent revealed by their preferences, but are also inextricable from our own values, once we understand the latter broadly enough. The value of those living things that are presumably not at all open-endedly open (trees, microbes, etc.) is an event involving them and us and non-human animals. The value of the non-living depends upon the valuations of open beings, and the value of the both the former and the latter is enriched further by the depth or fullness of world - of community - made possible by the existence of open-ended openness. Dasein or something akin to it, relatively widespread and broadly reciprocal.

For these reasons then, we believe that philosophy has a vital role to play in the project of valuing nature. There is a grave danger in the fact that at present the "Valuing Nature" project and the "TEEB" project do not contain explicit philosophising. The danger is that they will be dominated by an implicit philosophy, by an outdated merely-humanist ethic that has a rampantly insufficient appreciation even of our humanity. Human beings value more than is dreamt of in this implicit philosophy. Philosophy is needed if such projects are to take account of the ecological condi- 
tions of valuation and to develop and deploy a properly ecological concept of value. Potential for doing so can be found in the "Valuing Nature" project, which does recognize the noninstrumental value of biodiversity and healthy ecosystems. But it tends to overlook or inadequately address the ecological conditions for such valuation. Once cost-benefit analysis of various projected futures has been carried out, the approach theoretically allows various kinds of valuation to be brought to bear so as to veto policies leading to some scenarios, even if they are the "best" scenarios according to the analysis. This is a welcome step in the right direction. However, the attempt to preserve the purely quantitative analysis from such "external" cares, concerns, and values remains troubling. Rather than the blunt instrument of veto after the fact, such "externalities" ought to be internalized into the very notion of the valuations taking place. We need to find a way of sufficiently acknowledging in our policy processes the valuableness of beings and places that are truly beyond price.

The economics of ecological valuation needs to move beyond first appearances and initial desires that have been bound to ideals of functionality, instrumentality and homogenizing anthropomorphism. Collectively, we must provide some genuine space for the critical "places" - the non-place - where value truly resides. We must somehow find a way of leaving enough space for the valuable that is not merely human, all-too-human. 